\title{
Pediatric case of presacral ganglioneuroma: diagnostic considerations and therapeutic strategy
}

\author{
Saloua Ammar ${ }^{1,2^{*}}$ (D), Taycir Cheikhrouhou ${ }^{1,2}$, Mohamed Jallouli ${ }^{1,2}$, Rahma Chtourou ${ }^{1,2}$, Sahla Sellami ${ }^{1,2}$,
} Hayet Zitouni ${ }^{1,2}$ and Riadh Mhiri, ${ }^{1,2}$

\begin{abstract}
Background: Ganglioneuroma (GN) is an uncommon tumor belonging to the neuroblastic tumors group and is often localized in the posterior mediastinum, retroperitoneum, and adrenal gland. Presacral (PS) location is extremely rare. Its management remains a challenge.

Case presentation: A 4-year-old child presented to our department for an isolated abdominal mass. Para-clinical exams concluded to PSGN. Subtotal surgical excision was performed through an anterior transperitoneal approach. The size of the residual tumor did not progress after the 6-year follow-up period and the patients were asymptomatic.

Conclusions: GN should be considered in the case of soft tissue presacral masses in pediatrics. Subtotal resection seems sufficient in case of an extension to the sacrum with low morbidity. The residual tumors are still stable and the prognosis seems conserved. Further, long-term follow-up in large studies is needed to confirm these findings.
\end{abstract}

Keywords: Ganglioneuroma, Pelvis, Diagnosis, Subtotal resection, Residual tumor

\section{Background}

Ganglioneuroma (GN) is a rare, benign, and slowgrowing tumor of the sympathetic nervous system originating from neural crest cells [1]. It accounts $0.1 \%$ to $0.5 \%$ of the nervous system tumors [2]. It may arise anywhere along the sympathetic chain, and the most common locations are the posterior mediastinum (41.5\%), retroperitoneum (37.5\%), adrenal gland (21\%), and neck (8\%) [3]. They are very rarely found in the PS space and fewer than 30 cases were reported in the literature $[4,5]$. The diagnosis using only imaging modalities still difficult [5-7]. Complete surgical resection is the treatment of choice [8]. However therapeutic abstention or incomplete resection is still discussed in some cases $[5,8,9]$. We report a case of a 4-year-old boy with pre-sacral GN and discuss the management.

\footnotetext{
* Correspondence: salouaammar@gmail.com

${ }^{1}$ Department of Pediatric Surgery, Hedi Chaker Hospital, Sfax, Tunisia

${ }^{2}$ University of Medecine of Sfax, Sfax, Tunisia
}

\section{Case presentation}

A 4-year-old boy with no remarkable past medical history presented to the hospital with hypogastric mass found by his mother one month later. He did not complain of clinical symptoms particularly abdominal pain, neurologic symptoms or, changes in bowel habits. Abdominopelvic examination confirmed the presence of a painless fixed and solid palpable hypogastric mass. Neurologic examination was normal. The blood pressure was normal.

Abdominal ultrasonography (US) revealed a solid pelviabdominal mass measuring $7.5 \times 5.7 \times 2.5 \mathrm{~cm}$ with its epicenter in the presacral space (Fig. 1A). Computed tomography (CT scan) was performed to better understand the nature and the extension of the mass. It revealed a heterogeneous mass measuring $9 \mathrm{~cm} \times 7.6 \mathrm{~cm} \times$ $7.2 \mathrm{~cm}$ with tissular density and irregular enhancement, arising from the sacral canal through the third right sacral foramen. A few punctate calcifications were 


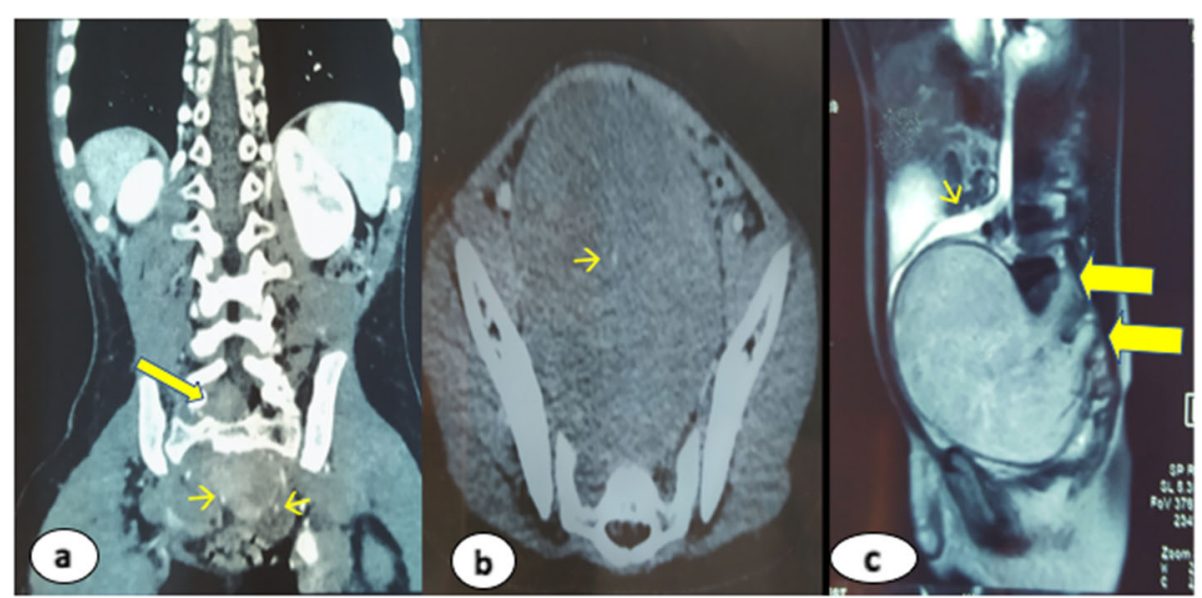

Fig. 1 Preoperative post contrast CT scan images in coronal plan (a) and axial plan (b) revealing a heterogeneous mass with the presence of calcific foci (thin yellow arrows) and sacral foraminal extension (thick yellow arrow). Preoperative MRI revealed hyperintensity on T2 weighted sagittal images where the mass had well-defined limits and foraminal extension (thick yellow arrows) anterior displacement of the ureter with subsequent hydronephrosis (thin yellow arrow) (c)

contained within the mass. Adjacent structures were displaced without invasion and no suspicious adenopathy was seen (Fig. 1B). Magnetic resonance imaging (MRI) was also performed to further characterize the mass. It revealed hypointensity on $\mathrm{T} 1$ weighted images and hyperintensity on T2 weighted images. The mass had well-defined limits and intraspinal extension, giving rise to a dumbbell-shaped lesion without intra-dural extension (Fig. 1C). After the evaluation of the lesion using imaging modalities, the diagnosis of a tumor from neural crest cells was evoked particularly neuroblastic tumor. Therefore, the patient had a CT scan guided fine-needle aspiration biopsy (FNAB) CT and dosage of urinary catecholamine and metaidobenzyl guanidine scintigraphy (MIBG). Vanilmandelic acid (VMA) and homovanilic acid (HVA) were slightly elevated $(17.5 \mu \mathrm{mol} / \mathrm{l}$ and 21 $\mu \mathrm{mol} / \mathrm{l}$, respectively). MIBG showed no fixation. Thoraco-abdominal CT scan showed no metastasis. Microscopic examination of the biopsy sections showed connective tissue with spindle cells with elongated and wavy nuclei. Large normal ganglionic cells were also noted. There was no neuroblastic component. No mitoses were seen. Postoperative histopathologic study concluded to $\mathrm{GN}$ and there were no stigmata of neuroblastoma.

Subtotal surgical excision of the GN was decided in front of the displacement of the adjacent structures. Laminectomy or foraminotomy was not performed in front of the absence of radicular symptoms. Anterior trans-peritoneal laparotomy was performed. There was a well-limited solid and pearly-white mass measuring 10 $\mathrm{cm} \times 9 \mathrm{~cm}$ tenaciously sticking to the sacral plane. Incomplete resection was performed and a residual tumor measuring $2 \mathrm{~cm}$ adherent to the sacrum was left in the pelvis. Postoperative course was marked by transient paresthesia and numbness in the right foot that disappeared spontaneously after 6 days.

The patient was followed regularly with physical examination, catecholamine's dosage, and the US. Abdominal CT scan or MRI was performed in case of suspicion of tumor progression. Postoperative ultrasonography completed by a CT scan showed residual tumor measuring

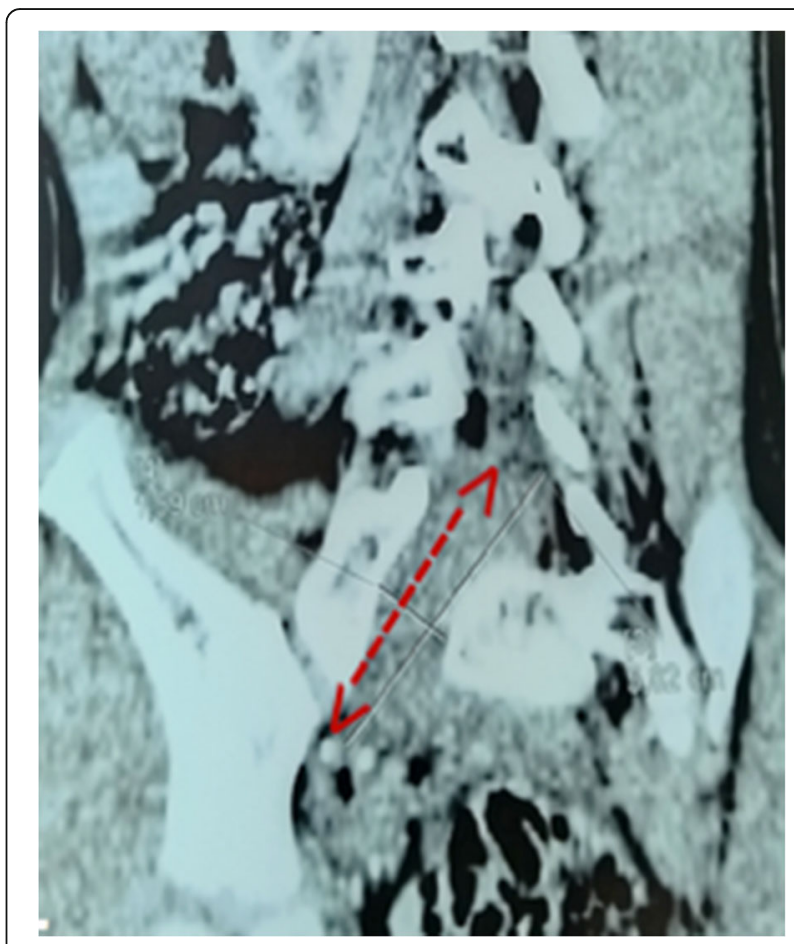

Fig. 2 Postoperative post-contrast CT scan showed residual tumor measuring $23 \times 8 \mathrm{~mm}$ (red arrow) 
$23 \times 8 \mathrm{~mm}$ (Fig. 2) which remains stable during 6 years of follow-up without malignant transformation. The patient is still asymptomatic.

\section{Discussion}

GNs are more frequent in older children than are neuroblastomas and ganglioneuroblastomas and typically seen in or after the second decade of life [1]. The median age at diagnosis is 7 years. For PS location, the median age at diagnosis is 35.5 years ranging from 5 to 70 years [9]. PSGN in the pediatric population is very rare. To our knowledge, only 6 pediatric cases were reported in literature [10-15]. Our patient is the youngest one.

These tumors are generally asymptomatic because they grow slowly and are usually detected incidentally at a late stage as a large palpable mass or when they compress and displace adjacent structures [2,7]. It may also progress into the spinal canal through the intervertebral foramen, forming a dumbbell-shaped tumor [6]. A variety of nonspecific symptoms have been attributed to local mass effects on adjacent structures. For PSGN, low back and leg pain, bilateral hip pain, constipation, amenorrhea, and neurogenic bladder have been reported in various studies as main symptoms. Our patient was incidentally detected when his mother noticed his pelviabdominal mass.

It is difficult to diagnose $\mathrm{GN}$ using imaging modalities only $[9,10]$. In front of a pelviabdominal mass with its epicenter in the presacral space, several differential diagnoses have to be considered. In the case of cystic mass, it may be rectal duplication or teratoma. If it is tissular mass, then tumors issued from the neural crest cells should be evoked such neuroblastic tumor, schwannoma, or meningioma. Other malignant tumors may have PS locations like Ewing-Tumor or sarcoma or lymphoma but they generally invade adjacent structures and erode bones. To better identify the nature and the extent of the PS masses, the gold standard imaging techniques are CT scan and MRI. Homogenous and circumscribed masses are found on CT in the case of GN. Circumscribed and fine calcification may be observed in $20 \%$ of the patients [5, 7]. On MRI, T1-weighted images show a low signal intensity, whereas T2-weighted images show a heterogeneous high signal intensity [16].

Distinct radiological features may lack. The diagnosis can, therefore be challenging and more precisely concluded using the histological examination. The biopsy may provide valuable information which guides therapeutic decision. However, complete analysis of the resected specimen remains necessary to detect intermixed neuroblastoma or pheochromocytoma within GN. In our case, biopsy concluded to GN but VMA and HVA were slightly elevated. GN may secrete sufficient quantities of VMA or HVA to manifest with flushing and other symptoms of catecholamine excess, GN rarely produces vasoactive intestinal polypeptide, androgenic hormones, and catecholamine. In patients with hormone-producing tumors, flushing, diarrhea, and labile hypertension could be observed [3].

$\mathrm{GN}$ is the mature form of neuroblastic tumors that is why complete surgical excision is the treatment of choice and it is usually curative. Nevertheless, incomplete resection is warranted, if necessary, to minimize surgery-related complications and to reduce surgeryrelated morbidity and mortality [17]. Some studies reported that incomplete resection was not associated with an increased risk of progression if residuals were smaller than $2 \mathrm{~cm}$. Others reported that residual GN after incomplete resection remains stable for years without malignant transformation [18]. Retrosi et al. did not observe recurrences after incomplete excision in a series of 23 children with different locations of GN [17].

The surgical approach is discussed according to the location of the tumor and the choice of the surgeon $[4,5]$. A posterior trans-sacral approach may be performed to remove a tumor completely involving the sacral nerve root but there is potential morbidity to the dural sac and lesion of pelvic structures which are not seen. The anterior retroperitoneal approach may be performed mainly in the case of lateral PSGN. In our case the tumor was medial and the anterior transperitoneal approach provided excellent access to the lesion.

Postoperative chylous ascites are rare complication due to the increase in extended resections and lymph node dissections. It may present a critical clinical situation due to the serious mechanical, nutritional, and immunological consequences of the constant loss of protein and lymphocytes. Various management modalities may be used successfully to treat chylous ascites. Therefore, treatment is usually individualized and adjusted to the severity of lymphatic leakage and its consequences [19-21]. Our patient was treated conservatively, with dietary support including high-protein and low-fat diets supplemented with medium-chain triglycerides, therapeutic paracentesis, total parenteral nutrition, and somatostatins.

The prognosis after surgical resection of GN, even if it is subtotal seems to be excellent. Nor neoadjuvant nor adjuvant chemotherapy or radiotherapy are indicated due to the benign nature of the disease $[3,5,22,23]$. Long-term clinical and radiological follow-up after incomplete resection is necessary, because the local progression of the residual tumor, recurrence of symptoms, and malignant transformation may occur [5, 7, 23, 24]. Redo surgery would be discussed only in the case of progression of the residual tumor more than $25 \%$ of the initial size [8] or malignant transformation. 


\section{Conclusions}

GN should be considered in case of soft tissue presacral masses in pediatrics. Subtotal resection seems sufficient in case of an extension to the sacrum with low morbidity. The residual tumors still stable and the prognosis seems conserved. Further long-term follow-up in large studies is needed to confirm these findings.

\section{Abbreviations}

GN: Ganglioneuroma; PS: Presacral; US: Abdominal ultrasonography; $\mathrm{CT}$ : Computed tomography; MRI: Magnetic resonance imaging; FNAB: Fineneedle aspiration biopsy; MIBG: Metaidobenzyl guanidine scintigraphy; VMA: Vanilmandelic acid; HVA: Homovanilic acid

\section{Acknowledgements}

Not applicable

\section{Authors' contributions}

SA: Conception, data analysis, draft the manuscript, revised the manuscript, and approved the submission. TC: Draft the manuscript, revised the manuscript and approved the manuscript. MJ: Conception, data analysis, revised the manuscript, and approved the manuscript. RC: Data analysis, revised the manuscript, and approved the manuscript. SS: Acquisition and analysis, revised the manuscript, and approved the manuscript. HZ: Revised the manuscript and approved the manuscript. RM: Revised the manuscript and approved the manuscript. The authors have read and approved the manuscript.

\section{Funding}

Not applicable.

\section{Availability of data and materials}

Not applicable

\section{Declarations}

\section{Ethics approval and consent to participate}

Approval form was obtained from the Hedi Chaker Hospital institutional review board.

\section{Consent for publication}

Written informed consent was obtained from the parents for publication of this case report and accompanying images.

\section{Competing interests}

All authors declare that they have no competing interests.

Received: 26 January 2021 Accepted: 25 May 2021

Published online: 11 August 2021

\section{References}

1. Kocaoglu M, Frush DP. Pediatric Presacral Masses. RadioGraphics. 2006;26(3): 833-57. https://doi.org/10.1148/rg.263055102.

2. Shimada H, Ambros IM, Dehner LP, Hata J, Joshi W, Roald B. Terminology and morphologic criteria of neuroblastic tumors: recommendations by the International Neuroblastoma Pathology Committee. Cancer. 1999;86(2):34963. https://doi.org/10.1002/(SICI)1097-0142(19990715)86:2<349::AID-CNCR2 $0>3.0 . \mathrm{CO} ; 2-\mathrm{Y}$.

3. Geoerger B, Hero B, Harms D, Grebe J, Scheidhauer K, Berthold F. Metabolic activity and clinical features of primary ganglioneuromas. Cancer. 2001; 91(10):1905-13. https://doi.org/10.1002/1097-0142(20010515)91:10<1905::A ID-CNCR1213>3.0.CO;2-4

4. Lee D, Choe WJ, Lim SD. Ganglioneuroma of the Sacrum. Korean Journal of Spine. 2017;14(3):106-8. https://doi.org/10.14245/kjs.2017.14.3.106.

5. Modha A, Paty P, Bilsky MH. Presacral ganglioneuromas. Report of five cases and review of the literature. J Neurosurg Spine. 2005;2(3):366-71. https://doi. org/10.3171/spi.2005.2.3.0366.

6. Sobowale O, Ibrahim I, du Plessis D, Herwadkar A, Tzerakis N. Dumbbell ganglioneuroma mimicking lumbar neurofibroma: a case report and review of the literature. Br J Neurosurg. 2013;27(4):521-3. https://doi.org/10.3109/02 688697.2013.771142

7. Otal P, Mezghani S, Hassissene S, Maleux G, Colombier D, Rousseau H, et al. Imaging of retroperitoneal ganglioneuroma. Eur Radiol. 2001;11(6):940-5. https://doi.org/10.1007/s003300000698.

8. Sánchez-Galán A, Barrena S, Vilanova-Sánchez A, Martín SHA, LopezFernandez S, García P, et al. Ganglioneuroma: to operate or not to operate. Eur J Pediatr Surg. 2014;24(1):25-30. https://doi.org/10.1055/s-0033-1358790.

9. Cerullo G, Marrelli D, Rampone B, Miracco C, Caruso S, Di Martino M, et al. Presacral ganglioneuroma: a case report and review of literature. World J Gastroenterol. 2007;13(14):2129-31. https://doi.org/10.3748/wjg.v13.i14.2129.

10. Vardas K, Manganas D, Papadimitriou G, Vougas V, Bakalis A, Chantziara M, et al. Presacral Ganglioneuroma: Diagnostic Considerations and Therapeutic Strategy. CRO. 2013;6:561-8.

11. Andersen HJ, Hansen LG, Lange P, Teglbjaerg PS. Presacral ganglioneuroma. Case report. Acta Chir Scand. 1986;152:777-8.

12. Spirnak JP, Wood BP. Pesacral ganglioneuroma. Am j dis child. 1993;147(10): 1119-20.

13. Lam CH, Nagib MG. Nonteratomatous Tumors in the Pediatric Sacral Region Spine. 2002;27:284-7.

14. Przkora R, Perez-Canto A, Ertel W, Heyde CE. Ganglioneuroma : primary tumor or maturation of a suspected neuroblastoma. Eur Spine J. 2006;15(3): 363-5. https://doi.org/10.1007/s00586-005-0964-9.

15. Roganović J. Pelvic ganglioneuroma-case report. Collegium antropologicum. 2010;34(2):683-5.

16. Scherer A, Niehues T, Engelbrecht $V$, Mödder U. Imaging diagnosis of retroperitoneal ganglioneuroma in childhood. Pediatr Radiol. 2001;31(2): 106-10. https://doi.org/10.1007/s002470000381.

17. Retrosi G, Bishay M, Kiely EM, Sebire NJ, Anderson J, Elliott M, et al. Morbidity after ganglioneuroma excision: is surgery necessary? Eur J Pediatr Surg. 2011;21(01):33-7. https://doi.org/10.1055/s-0030-1263195.

18. De Bernardi B, Gambini C, Haupt R, Granata C, Rizzo A, Conte M, et al. Retrospective study of childhood ganglioneuroma. J Clin Oncol. 2008;26(10): 1710-6. https://doi.org/10.1200/JCO.2006.08.8799.

19. Bhardwaj R, Vaziri H, Gautam A, Ballesteros E, Karimeddini D, Wu GY. Chylous Ascites: A Review of Pathogenesis, Diagnosis and Treatment. J Clin Transl Hepatol. 2018;6(1):105-13.

20. Leibovitch I, Mor Y, Golomb J, Ramon J. The diagnosis and management of postoperative chylous ascites. J Urol. 2002;167(2):449-57. https://doi.org/10.1 016/S0022-5347(01)69064-5.

21. Weniger M, D'Haese JG, Angele MK, Kleespies A, Werner J, Hartwig W. Treatment options for chylous ascites after major abdominal surgery: a systematic review. Am J Surg. 2016;211(1):206-13. https://doi.org/10.1016/j.a mjsurg.2015.04.012.

22. Chelli M, Mnif N, Bouhala T, Kara M, Kribi L, Kammoun A, et al. Pelvic ganglioneuroma. Case report. J Radiol. 2000;81(6):629-31.

23. Okai T, Minamoto T, Ohtsubo K, Takahashi Y, Kitagata H, Kadoya M, et al. Presacral ganglioneuroma arising in an elderly man with persistent constipation. Abdom Imaging. 2001;26(2):215-7. https://doi.org/10.1007/ s002610000133.

24. Yang C, Li C-C, Zhang J, Kong X-R, Zhao Z, Deng X-B, et al. Intermittent Fever, Progressive Weight Gain, and Personality Changes in a Five-Year-Old Girl: Unusual Paraneoplastic Syndrome due to Presacral Ganglioneuroma. Case Reports in Endocrinology. 2016;2016:2743576.

\section{Publisher's Note}

Springer Nature remains neutral with regard to jurisdictional claims in published maps and institutional affiliations. 